\title{
Community-based interventions to increase dairy intake in healthy populations: a systematic review
}

Zeinab Nikniaz ${ }^{1}$, Jafar Sadegh Tabrizi ${ }^{2}$, Morteza Ghojazadeh ${ }^{3}$, Mahdieh Abbasalizad Farhangi', Mohammad-Salar Hosseini ${ }^{5}$, Motahareh Allameh ${ }^{6}$, Soheila Norouzi ${ }^{7}$ and Leila Nikniaz ${ }^{2^{*}}$

* Correspondence: nikniazleila@ gmail.com

${ }^{2}$ Tabriz Health Services Management Research Center, Faculty of Management and Medical Informatics, Tabriz University of Medical Sciences, Tabriz, Iran

Full list of author information is available at the end of the article

\begin{abstract}
Background: Considering the low frequency of dairy intake in the population, interventions aiming to increase its consumption can be a priority for any health system.

Objective: This study aims to summarize community-based interventions for improving dairy consumption and their effectiveness to help policy-makers in designing coherent public health strategies.

Methods: This study was conducted in 2019, using PubMed/MEDLINE, Scopus, EMBASE, Cochrane Library, Web of Science, ProQuest, and Google Scholar. Two independent reviewers selected the eligible studies, and the outcomes of interest were extracted. The quality of eligible studies was assessed using the Joanna Briggs Institute Critical Appraisal Checklist for randomized controlled trials and quasiexperimental studies.
\end{abstract}

Results: Out of 521 initially identified articles, 25 studies were included. Interventions reported in 19 studies were effective in increasing dairy consumption. Interventions in high-income countries were more effective than those in middle- and low-income countries. Interventions in health centers and supermarkets were more effective than the community and school-level interventions. Interventions in supermarkets and adolescents as target groups were more effective than children, middle-aged people, and the elderly. Also, educational interventions and changing buying/selling pattern were more effective than multiple interventions. Interventions longer than 24 and 48 weeks were more effective than shorter interventions.

Conclusion: Three policy options including educational interventions, multiple interventions, and changing the purchase pattern are suggested. It seems that applying all of the interventions together can be more effective. Also, long-term and well-designed future studies in different settings are recommended to confirm these results.

Keywords: Community-based interventions, Dairy, Milk, Systematic review 


\section{Background}

Dairy is a rich source of proteins, vitamins, and minerals. It fulfills the vital needs of humans in different periods of life. So, consuming dairies has a great importance regardless of age [1]. Milk and dairy products are rich sources of calcium and magnesium [2]. These minerals are essential for the growth and strength of the bones, especially in children and adolescents due to rapid skeleton growth and bone condensation [3]. In addition, calcium is necessary for the natural mineralization of the bones and the matrix of cartilage [4]. According to the evidence, calcium can also reduce the risk of osteoporosis in the older population [5-8]. In adulthood, consuming dairy is associated with the risk reduction for some chronic diseases $[9,10]$. Increased intake of dairy products using a restricted diet can accelerate weight loss [11, 12]. The results of a systematic review showed that an average increase in the consumption of low-fat dairy (200 g per day) reduces the risk of diabetes [13]. Also, a meta-analysis of cohort studies demonstrated that total milk and dairy consumption have an inverse relation with the incidence of colorectal cancer [14]. Since dairy products have a proper amount of calcium, magnesium, and potassium-which play an important role in regulating blood pressure-they can be useful in decreasing blood pressure and preventing stroke [15].

According to studies, dairy intake is considered low among children and adolescents $[16,17]$. According to the United States Department of Agriculture (USDA), the daily recommendation of dairy for an adult with an energetic need of $2000 \mathrm{Kcal} /$ day is 3 portions per day, but the US population only consumes half of the recommendation (1.5 portions per day) [18]. Also, some other studies conducted in different age groups indicated that the intake was below the recommended daily amount of dairy [19-28].

Although dairy consumption has countless benefits for improving health issues, the amount of dairy intake is lower than the international recommendations [22-24, 29], which can lead to an increase in the incidence of certain diseases such as osteoporosis, diabetes, colorectal cancer, and hypertension as well as healthcare costs [30]. In order to identify policy options to increase dairy intake, reviewing successful community-based strategies and their effectiveness is needed to help policy-makers in choosing the best policy options with respect to situations in each country. Considering the numerous evidence available and the lack of a systematic review in this field, this study was conducted to evaluate community-based interventions for improving dairy consumption and their effectiveness to help policy-makers in designing coherent public health strategies.

\section{Methods}

The present systematic review attempted to evaluate the effect of community-based interventions to increase dairy intake in all population groups. The main outcome of the present study was an increase in the amount of dairy intake in a healthy population. The reporting procedures were according to the guidelines presented by Preferred Reporting Items for Systematic Reviews and Meta-Analysis (PRISMA) (Supplementary material) [31].

\section{Search strategy}

This systematic review was designed and conducted in 2019. Such databases as PubMed, Scopus, Google Scholar, Cochrane Library, Science Direct, and Web of 
Science were systematically searched. The timeframe selected for searching articles was from 2000 to 2019. A number of prestigious journals in the field were also searched manually to identify and cover more articles, mainly the ones published after the database search was performed. After excluding articles which did not meet the inclusion criteria, the reference lists of the remaining articles were also searched to increase the reliability of identifying and reviewing the eligible articles. The databases of the European Association for Gray Literature Exploitation (EAGLE) and the Health Care Management Information Consortium (HMIC) were also searched for gray literature. The search strategy for PubMed was as follows: Search (dairy[Title/Abstract]) OR yoghurt[Title/Abstract]) OR yogurt[Title/Abstract]) OR milk[Title/Abstract] OR calcium[Title/ Abstract]) AND "community based"[Title/Abstract]) OR community-based[Title/Abstract]) OR population-based[Title/Abstract]) OR evidence-based[Title/Abstract]) OR "population based"[Title/Abstract]) OR practice[Title/Abstract]) OR education[Title/ Abstract]) OR "food policy"[Title/Abstract]) OR intervention[Title/Abstract]) OR implementation[Title/Abstract]) OR approach[Title/Abstract]) OR strategy[Title/Abstract]) AND "national program"[Title/Abstract]) OR country[Title/Abstract]) OR community[Title/Abstract]) NOT sheep[Title/Abstract]) NOT farm[Title/Abstract]) NOT cow[Title/Abstract]) NOT herd[Title/Abstract]) NOT lactation[Title/Abstract]) NOT newborn[Title/Abstract]) NOT infant[Title/Abstract]

\section{Inclusion and exclusion criteria}

Randomized clinical trials (RCTs) or quasi-experimental studies were included if they (i) enrolled all age groups of normal and healthy population, (ii) evaluated the effect of community-based intervention to increase dairy consumption, and (iii) were published in an English language journal.

Studies conducted on subjects with chronic diseases such as cardiovascular diseases, diabetes, and hypertension were excluded from the study. Also, studies which focused on calcium intake instead of dairy consumption were removed. Economic evaluations, modeling studies, laboratory and observational studies, and studies with the aim of tool development were also excluded. The research question based on PICO is available in Table 1.

\section{Study selection, data extraction strategy, and quality assessment}

Two reviewers extracted the data independently and screened the title and abstract of records to identify which potentially relevant records met the inclusion/exclusion criteria. Full-text articles were obtained for these records and were independently assessed

Table 1 Inclusion and exclusion criteria based on PICO

\begin{tabular}{|c|c|c|}
\hline PICO components & Inclusion criteria & Exclusion criteria \\
\hline Population & All ages and genders & Patients referring to healthcare centers \\
\hline Intervention & $\begin{array}{l}\text { Community-based interventions in order } \\
\text { to increase dairy/calcium consumption }\end{array}$ & $\begin{array}{l}\text { Clinical or laboratory interventions, intervention } \\
\text { on reducing the consumption of high-fat dairy }\end{array}$ \\
\hline Comparison & All ages and genders & Patients referring to healthcare centers \\
\hline Outcome & $\begin{array}{l}\text { Increase in amount or times of dairy } \\
\text { consumption }\end{array}$ & $\begin{array}{l}\text { Reducing the consumption of high-fat dairy, } \\
\text { increasing awareness, etc. }\end{array}$ \\
\hline Other criteria & Publications in English & $\begin{array}{l}\text { Observational studies, studies with the aim of } \\
\text { tool development }\end{array}$ \\
\hline
\end{tabular}


for relevance by the reviewers. The following information was extracted from the studies: author(s), year of publication, target population characteristics, country, methodological characteristics (study design), types and aims of intervention, and main outcomes. Countries were categorized as low-, middle-, and high-income according to the World Bank [32] for the current 2019 fiscal year. "Low-income economies were defined as those with a gross national income (GNI) of $\$ 995$ or less in 2017, which was calculated using the World Bank Atlas method; lower middle-income economies were those with a GNI per capita between $\$ 996$ and \$3895; upper middle-income economies were those with a GNI per capita between $\$ 3896$ and $\$ 12,055$; and high-income economies were those with a GNI per capita of $\$ 12,056$ or more". The quality of studies was assessed using the Joanna Briggs Institute Critical Appraisal Checklist for RCTs and Quasi-Experimental Studies. A flow chart of the literature review is shown in Fig. 1.

\section{Results}

Out of 521 results retrieved from databases and other mentioned sources, 241 were removed due to the duplicity among different sources. Reviewing the title and abstract of the results, 230 more studies were excluded due to incompatibility with the study question and aim. After reviewing the full texts of the remaining articles, 25 other studies were removed; finally, 25 articles were included in the study (Fig. 1).

The data and characteristics of the 25 reviewed articles are presented in Tables 2 and 3. Out of the 25 reviewed articles, 23 were in high-income countries. Most studies ( $n: 16)$ were conducted in the USA. The studies could be divided into four categories based on the context: at the community level (n: 6), schools ( $n: 11)$, health centers $(n: 5)$, and markets $(n: 3)$. Also, most studies $(n: 16)$ were randomized controlled trials.

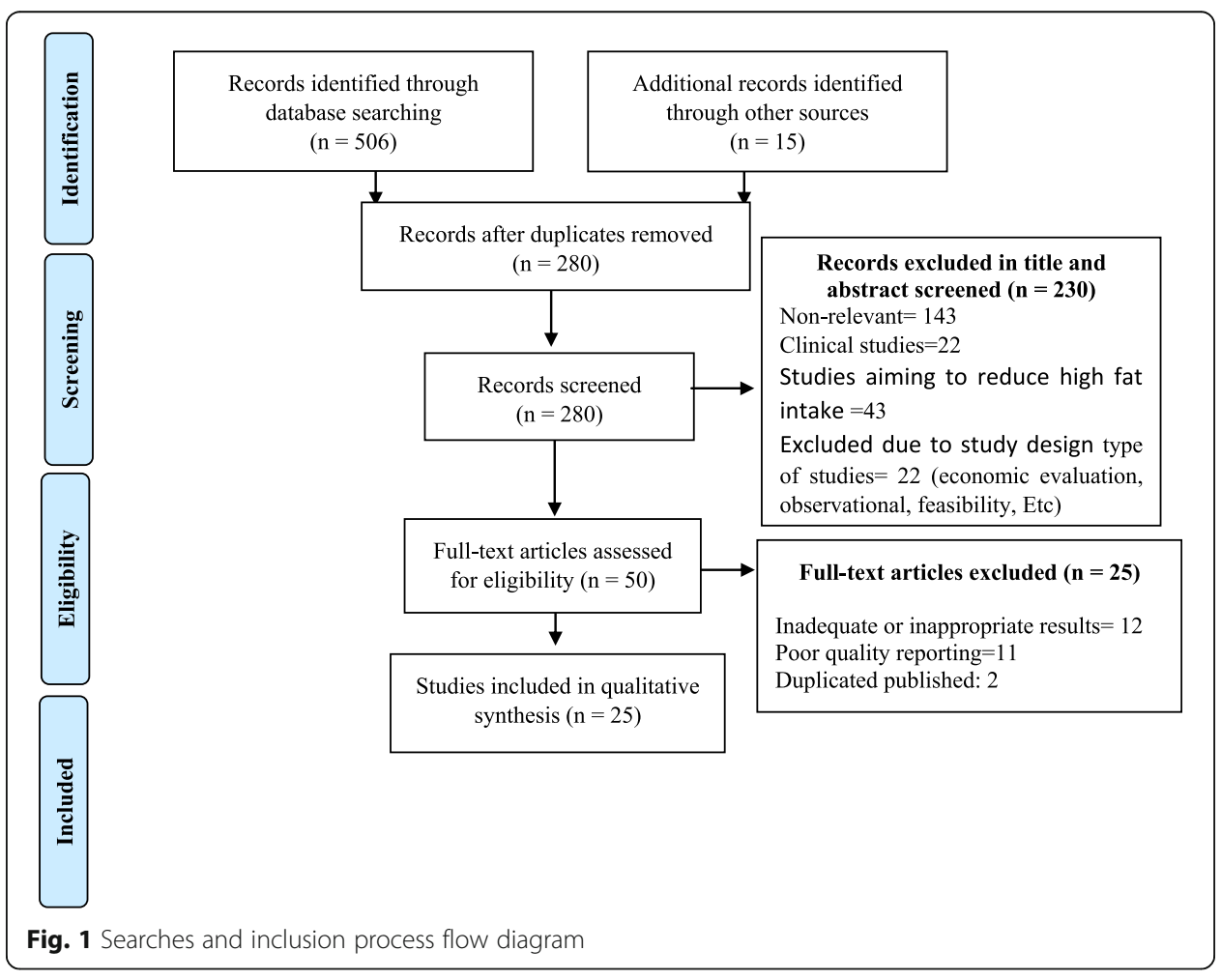


Participants in four studies were adults and the elderly. Meanwhile, children and adolescents were the point of research in 2 and 17 studies, respectively. Totally, the number of subjects in the intervention and control groups was 6939 and 6753, respectively.

Educational interventions were used in 19 studies. In addition, three studies focused on the sale and providing dairy products and three studies used multiple-level interventions. In six studies, increasing the intake of dairy products was the primary goal and in 19 studies multi-component aims were applied. Regarding the duration of interventions, a maximum of 350 weeks and a minimum of 5 weeks were performed. The intervention was repeated daily in six studies, once a week in 13 studies, once every 2 weeks in 4 studies, and every month in 1 study. In one study, the time of repeating the intervention was not mentioned [34].

\section{Location/field of study}

The majority of studies were performed at school level ( $n$ : 11), of which six studies were effective in increasing dairy intake. There were 6 studies at the community level, of which 4 were effective. There were 5 studies in health centers, all of which confirmed the effectiveness of the interventions. Fewer interventions were performed in the supermarkets ( $n: 3)$; the results of all 3 studies showed the effectiveness of the interventions.

\section{Target group}

Adolescent groups were the most common target groups (n: 17), with a total of 12 studies confirming the effectiveness of the interventions. Children were the target group in two studies, of which none were effective. The adults and older people were the target group of four studies, three of which were effective. The supermarket intervention was in three studies, all of which were effective in increasing the intake of dairy products.

\section{Type of intervention}

Most of the studies ( $n$ : 19) were educational, including training with physical exercise, home visits, telephone calls, using the web and technology tools, etc. with approximately $70 \%$ of studies succeeding in the increase of dairy consumption when using this type of intervention [33, 36-39, 43, 47, 49,56]. There were two educational interventions performed among the elderly people, including home visits and telephone followups; both interventions were successful [33, 51]. In the children and adolescents' group, interventions were training through technology tools [34, 36, 38, 44, 45], peer education in schools $[36,38,40,42,45,46]$, pamphlets $[43,45,46,54]$, and training with snacks $[40,48]$.

Multiple interventions ( $n: 2)$ also included public advertisement and lowered prices for healthy products in schools or supermarkets; all of these interventions were effective $[40,50]$.

Providing dairy products for children in schools [41, 48], and increased exposing with the recommended products or prime placement of healthy products in markets were some other types of interventions [53]. 
Table $\mathbf{2}$ Characteristics of the included studies

\begin{tabular}{|c|c|c|c|c|c|}
\hline \multirow[t]{2}{*}{ Author, year } & \multirow[t]{2}{*}{ Country } & \multirow[t]{2}{*}{ Setting } & \multirow{2}{*}{$\begin{array}{l}\text { Study } \\
\text { design }\end{array}$} & \multicolumn{2}{|l|}{ Participants } \\
\hline & & & & Intervention & Control \\
\hline \multirow[t]{2}{*}{ Kimura, et al. 2013 [33] } & \multirow[t]{2}{*}{ Japan } & \multirow[t]{2}{*}{ Community } & \multirow[t]{2}{*}{$\mathrm{RCT}$} & \multicolumn{2}{|c|}{ Older adults aged $65-90$ years } \\
\hline & & & & 57 & 35 \\
\hline \multirow[t]{2}{*}{ Duncanson, et al. 2013 [34] } & \multirow[t]{2}{*}{ Australia } & \multirow[t]{2}{*}{ Health car facilities } & \multirow[t]{2}{*}{$\mathrm{RCT}$} & \multicolumn{2}{|c|}{ Parent-child dyads aged $2.0-5.9$ years) } \\
\hline & & & & 75 & 71 \\
\hline \multirow[t]{2}{*}{ McCarthy, et al. 2007 [35] } & \multirow[t]{2}{*}{ USA } & \multirow[t]{2}{*}{ Community } & \multirow[t]{2}{*}{$\mathrm{RCT}$} & \multicolumn{2}{|c|}{$\begin{array}{l}\text { Predominantly overweight or obese } \\
\text { healthy women aged } 23-77 \text { years }\end{array}$} \\
\hline & & & & 188 & 178 \\
\hline \multirow[t]{2}{*}{ Casazza, et al. 2006 [36] } & \multirow[t]{2}{*}{ USA } & \multirow[t]{2}{*}{ High schools } & \multirow[t]{2}{*}{ Qu } & Adolescent stu & aged 14-19 years \\
\hline & & & & 2565 & 1599 \\
\hline DeBar, et al. 2006 [37] & USA & Health care & $\mathrm{RCT}$ & Students age & to 16 years \\
\hline & & taclilt & & 101 & 108 \\
\hline DeBar, et al. 2009 [38] & USA & Health care & $\mathrm{RCT}$ & Students age & to 16 years \\
\hline & & & & 82 & 41 \\
\hline Dawson 2006 [39] & USA & Middle school & Qu & Students in $\mathrm{g}$ & 7 and 8 \\
\hline & & & & 45 & 18 \\
\hline Gates, et al. (1) 2013 [40] & Canada & Middle school & $\mathrm{Qu}$ & Students age & 15 years \\
\hline & & & & 26 & No control \\
\hline Gates, et al. (2) 2013 [41] & Canada & Middle school & Qu & Students in $\mathrm{g}$ & 6 to 8 \\
\hline & & & & 70 & No control \\
\hline Lo, et al. (2008) [42] & Canada & Middle school & $\mathrm{Qu}$ & Students in $\mathrm{g}$ & \\
\hline & & & & 53 & 48 \\
\hline $\begin{array}{l}\text { Naghashpour, et al. } \\
2014 \text { [43] }\end{array}$ & Iran & High school & $\mathrm{RCT}$ & $\begin{array}{l}\text { Female stude } \\
\text { school }\end{array}$ & junior high \\
\hline & & & & 95 & 93 \\
\hline Olson, et al. 2008 [44] & USA & Health care & $\mathrm{RCT}$ & Healthy teens & d1-20 \\
\hline & & taclli & & 136 & 148 \\
\hline O'Connell, 2005 [45] & USA & Middle school & $\mathrm{RCT}$ & Students in $\mathrm{g}$ & \\
\hline & & & & 220 & 269 \\
\hline Singhal, et al. 2010 [46] & India & High school & $\mathrm{RCT}$ & students in $\mathrm{g}$ & \\
\hline & & & & 99 & 102 \\
\hline Watson, et al. 2009 [47] & USA & High school & $\mathrm{Qu}$ & Students age & 19 years \\
\hline & & & & 45 & 30 \\
\hline Wordell, et al. 2012 [48] & USA & Middle school & Qu & Students in $\mathrm{g}$ & 7 and 8 \\
\hline & & & & 1406 & 2707 \\
\hline Yamaoka, et al. 2011 [49] & Japan & Community & $\mathrm{RCT}$ & Female adole & s aged 13-15 \\
\hline & & & & 225 & 234 \\
\hline Finnell, et al. 2017 [50] & USA & Supermarkets & $\mathrm{Qu}$ & Supermarkets & \\
\hline & & & & 80 & 66 \\
\hline Bernstein, et al. 2002 [51] & USA & Community & $\mathrm{RCT}$ & Men and wor & older than age 69 \\
\hline & & & & 38 & 32 \\
\hline Ni Mhurchu, et al. 2010 [52] & New & Supermarkets & $\mathrm{RCT}$ & Shoppers (ad & \\
\hline & & & & 277 & 278 \\
\hline Foster, et al. 2014 [53] & USA & Supermarkets & $\mathrm{RCT}$ & Supermarkets & \\
\hline & & & & 4 & 4 \\
\hline
\end{tabular}


Table 2 Characteristics of the included studies (Continued)

\begin{tabular}{|c|c|c|c|c|c|}
\hline \multirow[t]{2}{*}{ Author, year } & \multirow[t]{2}{*}{ Country } & \multirow[t]{2}{*}{ Setting } & \multirow{2}{*}{$\begin{array}{l}\text { Study } \\
\text { design }\end{array}$} & \multicolumn{2}{|l|}{ Participants } \\
\hline & & & & Intervention & Control \\
\hline \multirow{2}{*}{$\begin{array}{l}\text { Freedman and Nickell. } \\
2010 \text { [54] }\end{array}$} & \multirow[t]{2}{*}{ USA } & \multirow[t]{2}{*}{ Community } & \multirow[t]{2}{*}{ Qu } & \multicolumn{2}{|c|}{ children aged 9 to 14 years } \\
\hline & & & & 49 & - \\
\hline \multirow[t]{2}{*}{ Friedman, et al. 2007 [55] } & \multirow[t]{2}{*}{ USA } & \multirow{2}{*}{$\begin{array}{l}\text { Health care } \\
\text { facilities }\end{array}$} & \multirow[t]{2}{*}{$\mathrm{RCT}$} & \multicolumn{2}{|c|}{ Children aged 8-10 years } \\
\hline & & & & 237 & 249 \\
\hline \multirow[t]{2}{*}{ Hovell, et al. 2009 [56] } & \multirow[t]{2}{*}{ USA } & \multirow[t]{2}{*}{ Community } & \multirow[t]{2}{*}{$\mathrm{RCT}$} & \multicolumn{2}{|c|}{ Children aged $10-13$ years } \\
\hline & & & & 68 & 49 \\
\hline \multirow{2}{*}{$\begin{array}{l}\text { Raby Powers, et al. } 2005 \\
\text { [57] }\end{array}$} & \multirow[t]{2}{*}{ USA } & \multirow[t]{2}{*}{ Elementary school } & \multirow[t]{2}{*}{ Qu } & \multicolumn{2}{|c|}{ Students in second and third grades } \\
\hline & & & & 702 & 398 \\
\hline
\end{tabular}

$R C T$ randomized controlled trial, $Q u$ quasi-experimental

\section{Increasing dairy products consumption as a main goal}

In six studies, increasing the intake of dairy products was the primary goal, of which four were effective (66.6\%). Moreover, of the 19 studies with other goals, 14 were effective $(73.6 \%)$ in increasing the intake of dairy products.

\section{Study duration}

The included studies were divided into four groups: studies with less than 8 weeks, including eight studies, of which four were effective; studies with nine to 24 weeks, including four studies, of which two were effective; studies with 24 to 48 weeks, including nine studies, of which eight were effective, and four studies with more than 48 weeks, of which all were effective.

\section{Intervention frequency}

Six studies were repeated daily (repetition due: 1 day), four of which were effective. Most studies ( $n$ : 13 ) had a weekly repeat interval, nine of which were effective. Four studies were repeated every 2 weeks, all of which were effective. Also, one study was repeated every 1 month, which was effective.

Interventions reported in 18 studies were effective in increasing dairy consumption and ineffective in seven studies. The effectiveness of the interventions based on the studied variables (country, location/field of study, participants, type of intervention, combination/specific dairy intervention, duration, and frequency) is shown in Table 4. In low- and middle-income countries (LMIC) and high-income countries 100\% and 70\% of the interventions were effective, respectively. Interventions in health centers and supermarkets were more effective than community- and school-level interventions. Interventions in adolescents as target groups were more effective than children, middleaged, and the elderly people. Also, multiple interventions and changes in buying/selling habits were more effective than educational interventions. Combined interventions to modify dairy intake were more effective than specific interventions. Interventions longer than 24 and 48 weeks were more effective than shorter interventions. Also, interventions repeated every 2 weeks and every month were more effective than interventions repeated daily or weekly. 


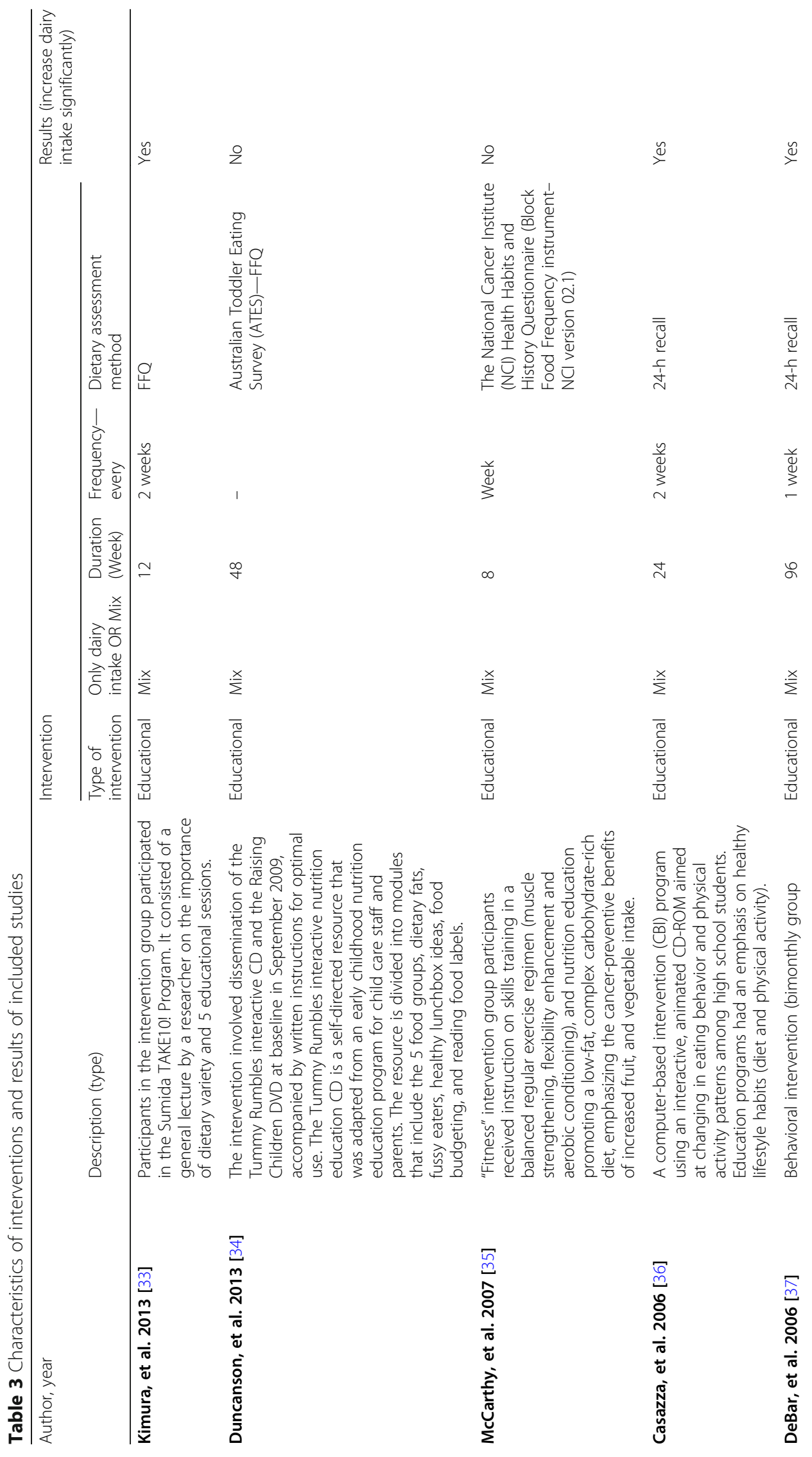




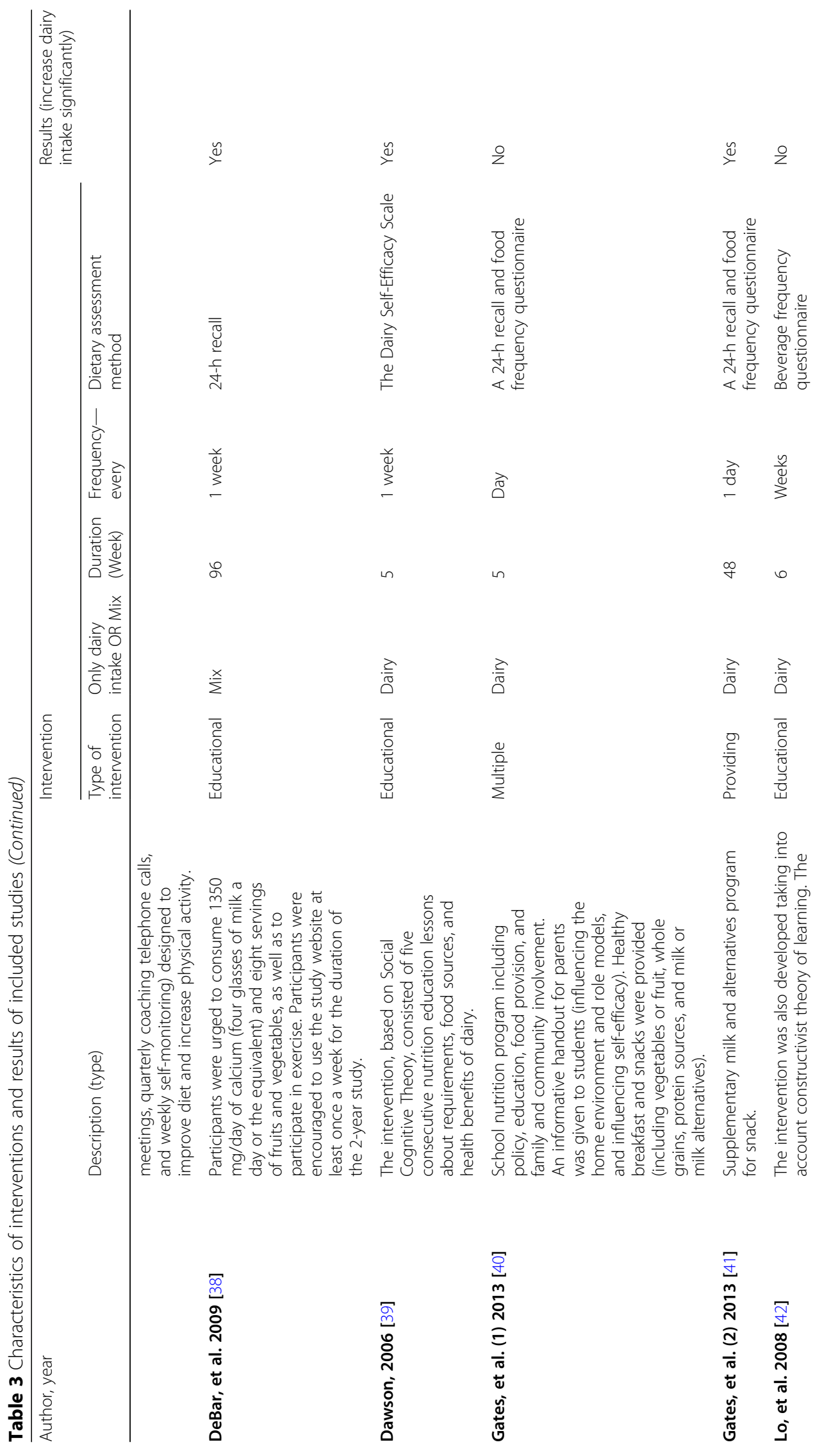




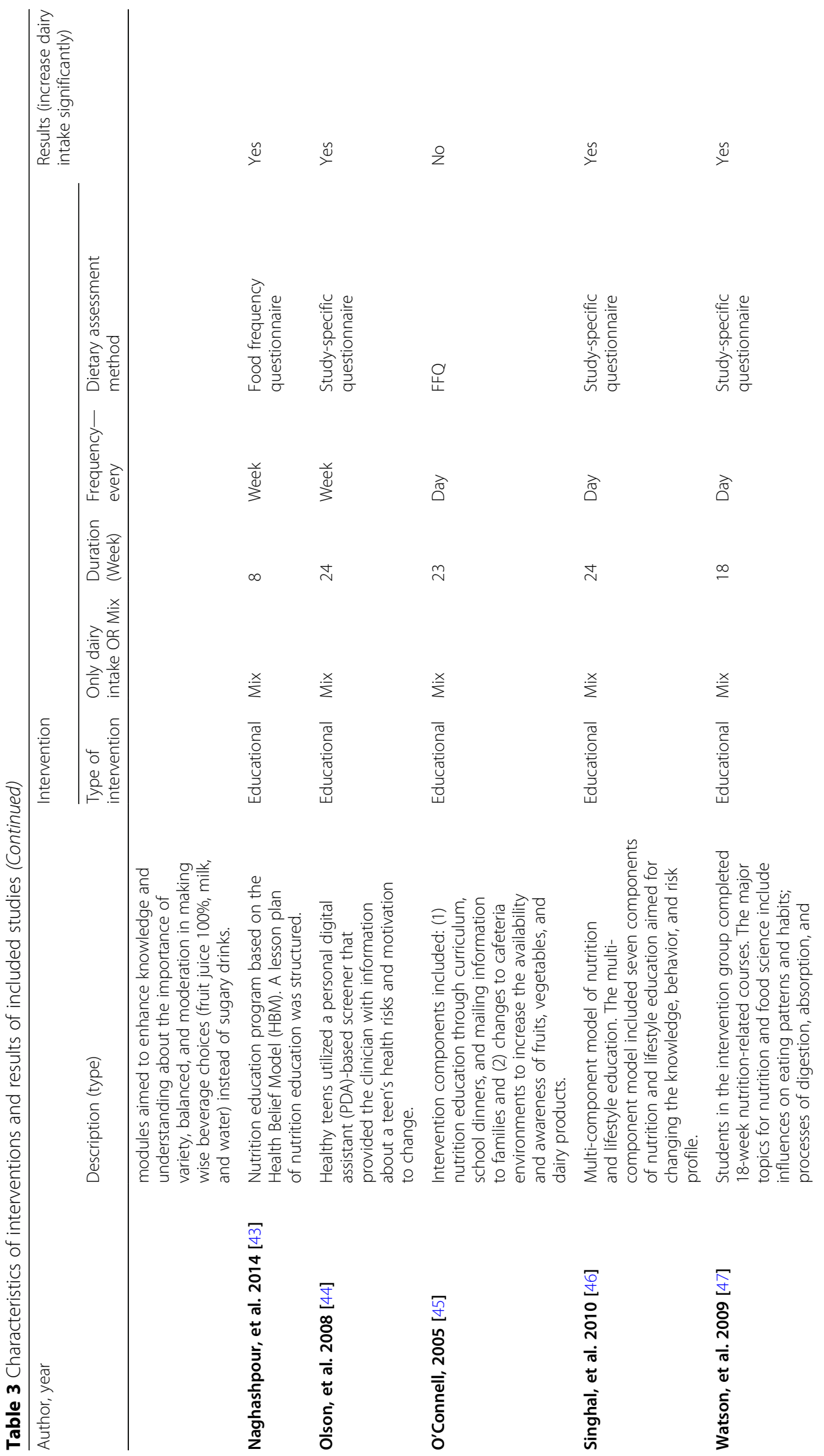




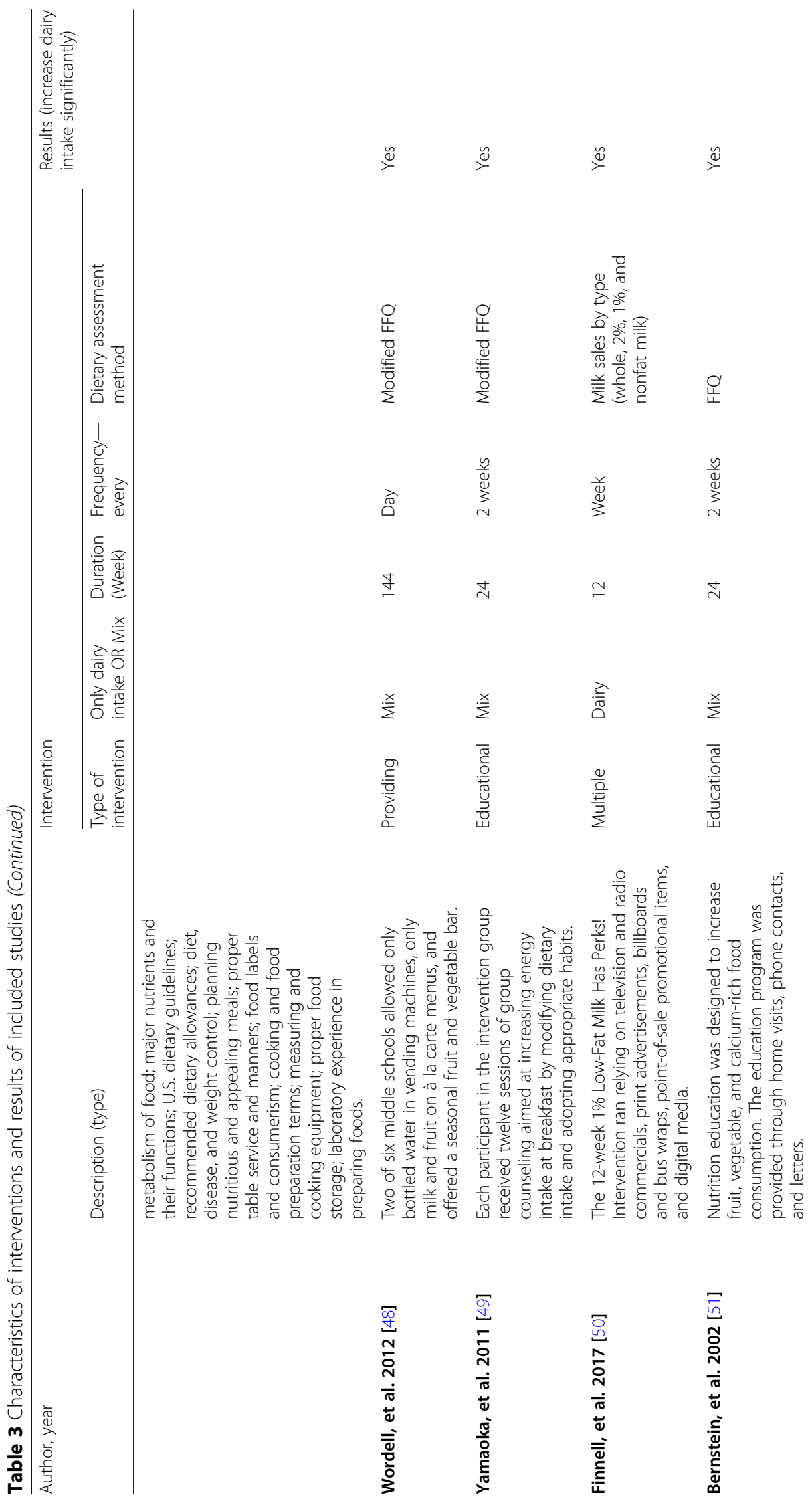




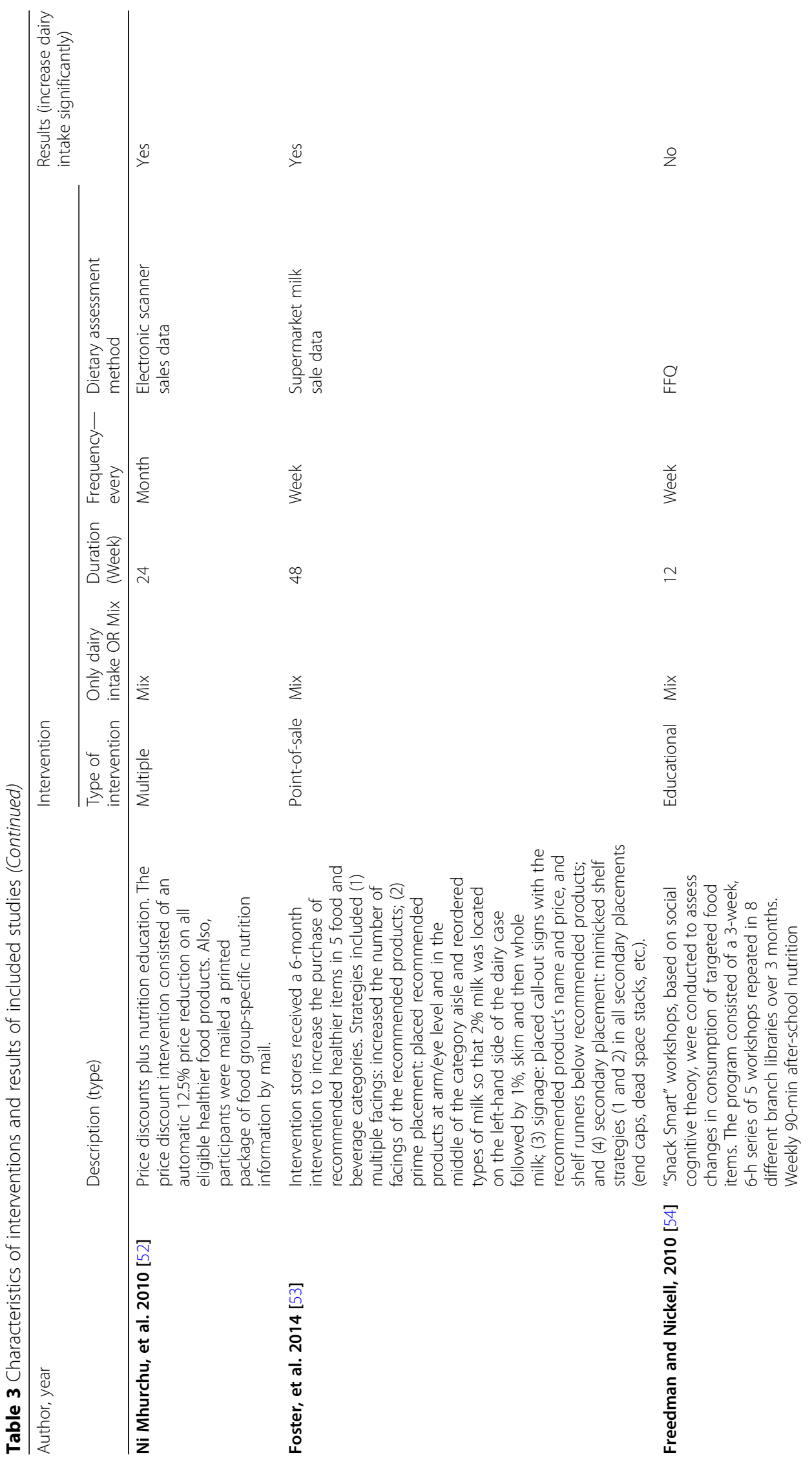




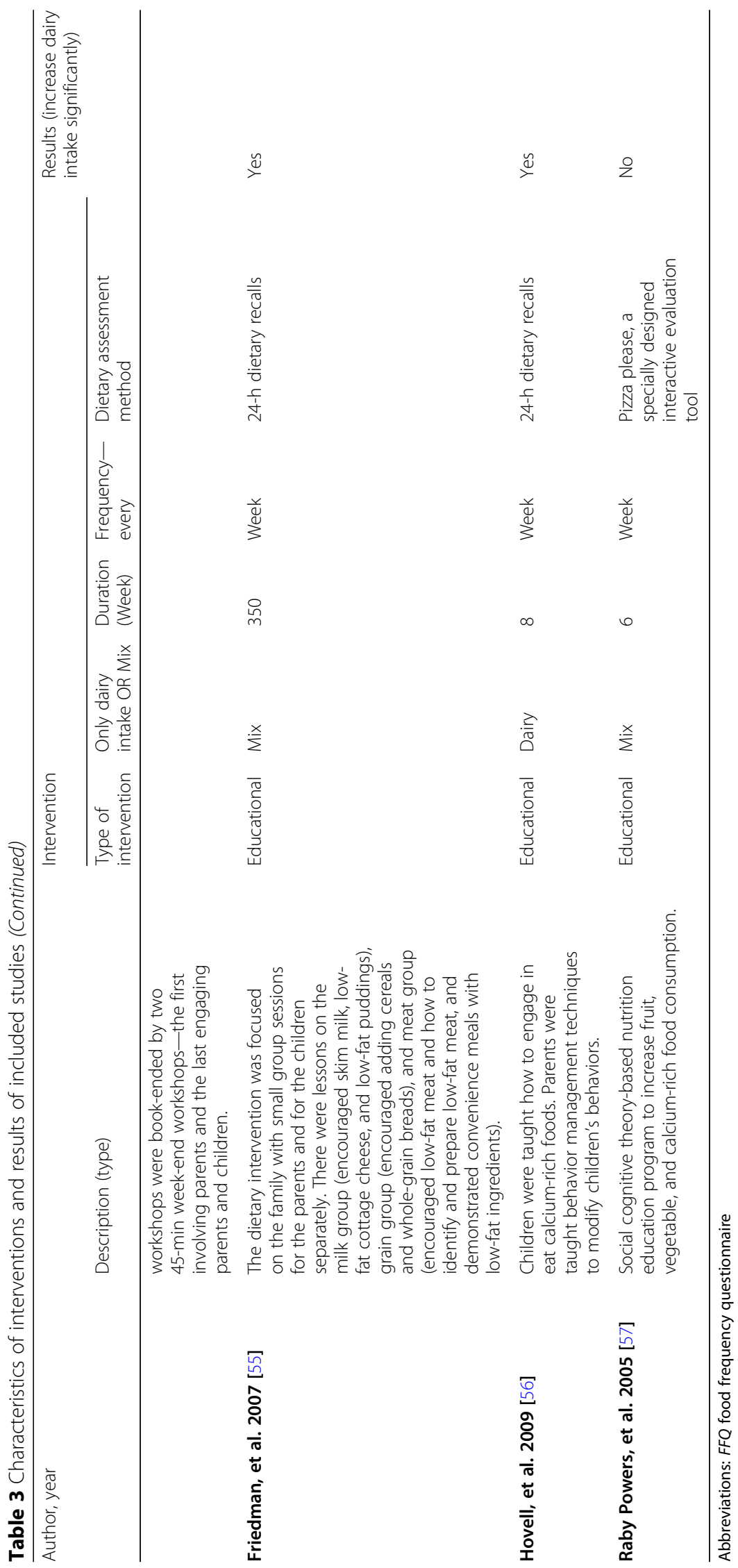


Table 4 The effectiveness of interventions on increasing dairy consumption based on the study

\begin{tabular}{|c|c|c|c|}
\hline Variable & Subgroups & $\begin{array}{l}\text { Number of } \\
\text { interventions }\end{array}$ & $\begin{array}{l}\text { Number of effective } \\
\text { interventions }\end{array}$ \\
\hline \multirow[t]{2}{*}{$\overline{\text { Country }}$} & High-income countries & 23 & 16 \\
\hline & $\begin{array}{l}\text { Low- and middle-income } \\
\text { countries (LMIC) }\end{array}$ & 2 & 2 \\
\hline \multirow[t]{4}{*}{ Location/context of study } & Community & 6 & 4 \\
\hline & Schools & 11 & 6 \\
\hline & Healthcare centers & 5 & 5 \\
\hline & Supermarkets & 3 & 3 \\
\hline \multirow[t]{4}{*}{ Participants } & Children & 2 & 0 \\
\hline & Adolescents & 17 & 12 \\
\hline & Adults and elders & 4 & 3 \\
\hline & Supermarkets & 3 & 3 \\
\hline \multirow[t]{3}{*}{ Type of intervention } & Educational & 19 & 13 \\
\hline & Multiple & 3 & 2 \\
\hline & $\begin{array}{l}\text { Change in purchase/sell } \\
\text { or providing }\end{array}$ & 3 & 3 \\
\hline \multirow{2}{*}{$\begin{array}{l}\text { Only dairy intake or } \\
\text { multicomponent intervention }\end{array}$} & Combination & 19 & 14 \\
\hline & Only dairy intake & 6 & 4 \\
\hline \multirow[t]{4}{*}{ Study duration } & 8 weeks and less & 8 & 4 \\
\hline & 9 to 24 weeks & 4 & 2 \\
\hline & 24 to 48 weeks & 9 & 8 \\
\hline & 48 weeks and more & 4 & 4 \\
\hline \multirow[t]{4}{*}{ Intervention frequency } & Everyday & 6 & 4 \\
\hline & Every week & 13 & 9 \\
\hline & Every 2 weeks & 4 & 4 \\
\hline & Every month & 1 & 1 \\
\hline
\end{tabular}

\section{Quality assessment of studies}

As can be seen in Tables 5 and 6, all studies had one or more domains characterized as high risk. Also, all studies had good quality in terms of having more low-risk domains than high-risk ones. Ten studies had selection bias due to a non-random selection of participants. Most of the studies had performance bias due to the unblinding of participants and personnel.

\section{Discussion}

Out of 521 retrieved articles, 25 were finally included in the study. The reported interventions were effective in increasing dairy consumption in 18 studies and ineffective in seven studies. As noted above, most interventions were conducted in high-income countries. This could be related to the greater research budgets. In high-income countries, different intervention methods and techniques had been used compared to lowand middle-income ones. The existing differences between these two groups of countries should be considered in applying the intervention types [58-60].

The results showed that the interventions performed in the healthcare centers and supermarkets were more effective than the community- and school-level interventions. 


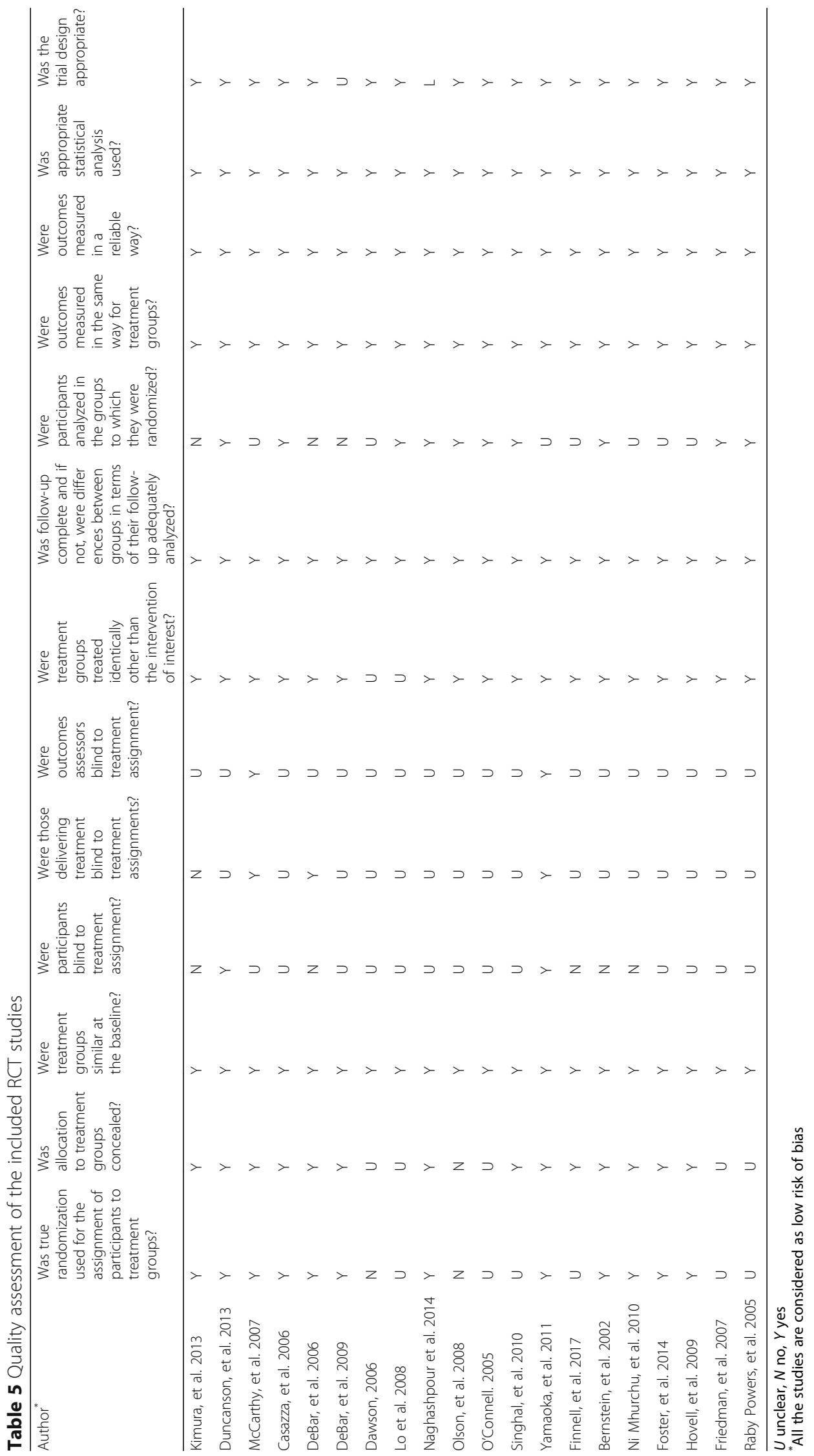




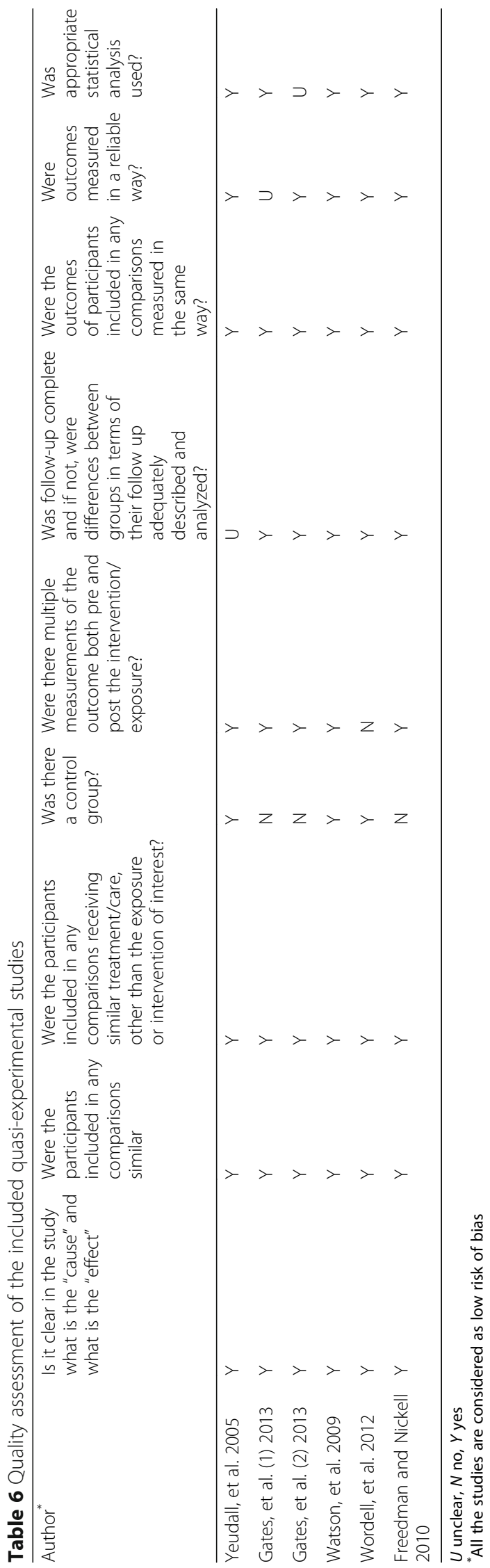


In addition, interventions in health centers are more acceptable and better adhered because of the psychological impact of these centers on participants. People who visit these centers tend to have a more positive attitude towards the role of the health system and they usually trust the recommendations of the health system [61-63]. Also, in community-based interventions, participants are usually adults and the elderly and changing food habits and behaviors in these groups is a really challenging task compared to children and adolescents. Therefore, it seems that designing and implementing interventions to increase dairy consumption can be better achieved if combined with the collaboration of the health system and the healthcare staff.

Regarding the effectiveness of interventions in supermarkets, all interventions in these centers were control/change interventions in the purchase of dairy products, which were much more effective. These interventions are usually made by offering discounts on dairy purchases (especially low-fat dairy) that appear to be a stronger incentive. It should be noted that a number of purchases were measured in these studies and the amount of dairy consumption was not assessed.

Based on the results, interventions on the children, the middle-aged, and the elderly people were less effective. The two studies performed in children applied multiple methods like policy changing, education, family and community involvement, and educational methods using educational CDs for children and parents. The duration of studies varied from 5 to 48 weeks. The results of review studies in different fields also indicate that the effectiveness of educational interventions on children is low [64-68]. The results of a systematic review and meta-analysis showed that interventions in adolescents were more effective in comparison with children [69]. Reasons for the lower effectiveness of interventions on children may be due to the low dose of the intervention [40], self-administered questionnaires which could lead children to under- or overestimate their intake [42], and lack of out-of-school nutrition programs [54].

Birch and colleagues have also stated that in order to improve primary school children's healthy food preferences, experiences and strategies are needed to increase availability and accessibility to increase exposure to those foods that will then affect their willingness to taste [70]. The low effectiveness of interventions in middle-aged and elderly people may also be attributed to the consolidation of dietary habits and other behaviors in these people; so modifying their behavior is very difficult [71, 72].

The results of our study showed that most of the interventions were educational, which had lower efficiency compared with interventions such as multiple interventions and changing the purchase patterns. The results of several systematic reviews support this finding [73, 74]. Although many experts believe that the effectiveness of educational interventions alone is in doubt, it seems that training can be effective if it is targeted and accompanied by other interventions to change behavior [75-77]. The findings of this study showed that providing dairy products is one of the effective methods to increase dairy intake. Wordell et al. demonstrated that healthful modifications in the school food environment are associated with positive food behaviors in early adolescents, but there was a cost associated with those changes. So, it seems that, if possible, providing dairy is a suitable way to increase the consumption of dairy products.

Interventions that lasted more than 24 weeks and repeated every 2 weeks and each month were more effective. The likely reason for the effectiveness of long-term 
interventions may be due to the effect of these interventions on the change of behavior and its stabilization. Because any short-term changes in human behavioral patterns can simply return to the basic state, but the longer-term change increases the likelihood of a sustained change in behavior [78, 79]. Possible reasons for the less effectiveness of interventions that were repeated less frequently (daily and weekly) might be that participants become bored. In addition, most of the interventions that were repeated less frequently were educational and multiple interventions, that were less effective than the other interventions.

The main advantage of our systematic review is the low risk of subjective data selection. Study searches, assessment, and data synthesis were based on predefined criteria and were performed using well-established tools by two independent reviewers. Nevertheless, our analysis had some limitations. First, publication bias cannot be excluded, i.e., ineffective interventions are less likely to be published. Potential limitations existing in the included studies are as follows: unclear or inadequate allocation concealment, no intention-to-treat analysis, inadequate information about controlling confounders, and applying different questionnaires for evaluating dairy intake. One of the most important limitations of the present study is the dispersion and variability of the reported indices for the effectiveness of interventions in the studies. Hence, performing a quantitative analysis (meta-analysis) was impossible.

\section{Conclusion}

According to the results of the present systematic review, three policy options including educational interventions, multiple interventions, and changing the purchase patterns are suggested. It seems that applying all of the interventions together can be more effective. Interventions in health centers and supermarkets are more effective than the community interventions. However, it should be noted that the implementation of the proposed interventions and settings depends on the limitations, resources, and facilities of different countries. So, long-term and high-frequency interventions focusing on increasing dairy products intake are suggested in different settings and countries.

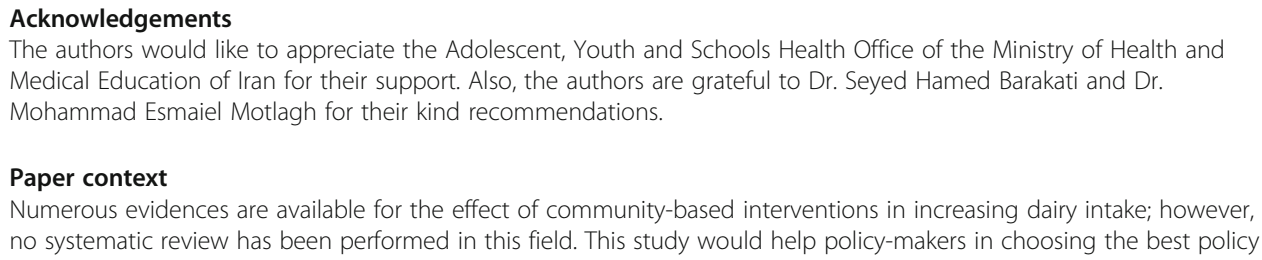




\section{Consent for publication}

Not applicable.

\section{Competing interests}

The authors declare that they have no competing interests.

\section{Author details}

${ }^{1}$ Liver and Gastrointestinal Diseases Research Center, Tabriz University of Medical Sciences, Tabriz, Iran. ${ }^{2}$ Tabriz Health Services Management Research Center, Faculty of Management and Medical Informatics, Tabriz University of Medical Sciences, Tabriz, Iran. ${ }^{3}$ Research Center for Evidence-Based Medicine, Tabriz University of Medical Sciences, Tabriz, Iran. ${ }^{4}$ Drug Applied Research Center, Tabriz University of Medical Sciences, Tabriz, Iran. ${ }^{5}$ Student Research Committee, Tabriz University of Medical Sciences, Tabriz, Iran. ${ }^{6}$ Adolescent, Youth and Schools Health Office, Ministry of Health and Medical Education, Tehran, Iran. ${ }^{7}$ Department of Human Nutrition, Faculty of Medicine, Qazvin University of Medical Sciences, Qazvin, Iran.

Received: 6 January 2020 Accepted: 18 June 2020

Published online: 04 August 2020

\section{References}

1. Givens D, Hobbs D. Milk and dairy products: dietary partners for life. Primary Health Care: Open Access. 2014;4:3.

2. Miciñski J, Zwierzchowski G, Kowalski IM, Szarek J. Health-promoting properties of selected milk components. J Elem. 2013;18(1):165-86.

3. Hendrie GA, Brindal E, Baird D, Gardner C. Improving children's dairy food and calcium intake: can intervention work? A systematic review of the literature. Public health nutrition. 2013;16(2):365-76.

4. Heaney RP. Dairy and bone health. J Am Coll Nutr. 2009;28(sup1):82S-90S.

5. Josse AR, Phillips SM. Impact of milk consumption and resistance training on body composition of female athletes. Med Sport Sci. 2012;59:94-103

6. Du X, Greenfield H, Fraser D, Ge K, Liu Z, He W. Milk consumption and bone mineral content in Chinese adolescent girls. Bone. 2002;30(3):521-8.

7. Eysteinsdottir T, Halldorsson T, Thorsdottir I, Sigurdsson G, Sigurðsson S, Harris T, et al. Milk consumption throughout life and bone mineral content and density in elderly men and women. Osteoporosis International. 2014;25(2):663-72.

8. Tu M-Y, Chen H-L, Tung Y-T, Kao C-C, Hu F-C, Chen C-M. Short-term effects of kefir-fermented milk consumption on bone mineral density and bone metabolism in a randomized clinical trial of osteoporotic patients. PloS one. 2015;10(12): e0144231.

9. Rice BH, Quann EE, Miller GD. Meeting and exceeding dairy recommendations: effects of dairy consumption on nutrient intakes and risk of chronic disease. Nutrition reviews. 2013;71(4):209-23.

10. Schulze MB, Martínez-González MA, Fung TT, Lichtenstein AH, Forouhi NG. Food based dietary patterns and chronic disease prevention. bmj. 2018;361:k2396.

11. Christensen R, Lorenzen JK, Svith CR, Bartels EM, Melanson EL, Saris WH, et al. Effect of calcium from dairy and dietary supplements on faecal fat excretion: a meta-analysis of randomized controlled trials. Obes Rev. 2009;10(4):475-86.

12. Chen M, Pan A, Malik VS, Hu FB. Effects of dairy intake on body weight and fat: a meta-analysis of randomized controlled trials. Am J Clin Nutr. 2012;96(4):735-47.

13. Gao D, Ning N, Wang C, Wang Y, Li Q, Meng Z, et al. Dairy products consumption and risk of type 2 diabetes: systematic review and dose-response meta-analysis. PLoS One. 2013;8(9):e73965.

14. Aune D, Lau R, Chan D, Vieira R, Greenwood D, Kampman E, et al. Dairy products and colorectal cancer risk: a systematic review and meta-analysis of cohort studies. Annals of oncology. 2012;23(1):37-45

15. Massey LK. Dairy food consumption, blood pressure and stroke. J Nutr. 2001;131(7):1875-8

16. Shokrvash B, Salehi L, Akbari MH, Mamagani ME, Nedjat S, Asghari M, et al. Social support and dairy products intake among adolescents: a study from Iran. BMC public health. 2015;15(1):1078.

17. Kranz S, Lin P-J, Wagstaff DA. Children's dairy intake in the United States: too little, too fat. J Pediatr. 2007;151(6):642-6 e2.

18. McGuire S. US department of agriculture and US department of health and human services, dietary guidelines for Americans, 2010. Washington, DC: US government printing office, January 2011. Oxford University Press; 2011.

19. Olmedo-Requena R, Amezcua-Prieto C, de Dios L-D-CJ, Lewis-Mikhael A-M, Mozas-Moreno J, Bueno-Cavanillas A, et al. Association between low dairy intake during pregnancy and risk of small-for-gestational-age infants. Matern Child Health J. 2016;20(6):1296-304

20. Campmans-Kuijpers MJ, Singh-Povel C, Steijns J, Beulens JW. The association of dairy intake of children and adolescents with different food and nutrient intakes in the Netherlands. BMC pediatrics. 2016;16(1):2.

21. Heaney RP. Dairy intake, dietary adequacy, and lactose intolerance. Advances in nutrition. 2013;4(2):151-6.

22. Xia W, Chiu YH, Afeiche MC, Williams PL, Ford JB, Tanrikut C, et al. Impact of men's dairy intake on assisted reproductive technology outcomes among couples attending a fertility clinic. Andrology. 2016;4(2):277-83.

23. Fernández $\mathrm{Cl}$, Flores SV. Brief Communication: lactase persistence and dairy intake in $\mathrm{M}$ apuche and $\mathrm{M}$ estizo populations from southern Chile. Am J Phys Anthropol. 2014;155(3):482-7.

24. Arshi S, Ghanbari B, Nemati K, Ekhtiari YS, Torkaman-nejad S, Kolahi A-A. Nutritional behaviors pattern of high school girls in North of Tehran. Community Health (Salāmat-i ijtimāī). 2016;2(1):19-30.

25. Dehdari T, Yekehfallah F, Rahimzadeh M, Aryaeian N, Rahimi T. Dairy foods intake among female Iranian students: a nutrition education intervention using a health promotion model. Glob J Health Sci. 2016;8(10):54893.

26. Moslehi N, Shab-Bidar S, Mirmiran P, Sadeghi M, Azizi F. Associations between dairy products consumption and risk of type 2 diabetes: Tehran lipid and glucose study. Int J Food Sci Nutr. 2015;66(6):692-9.

27. Nikniaz Z, Mahdavi R, Amiri S, Ostadrahimi A, Nikniaz L. Factors associated with body image dissatisfaction and distortion among Iranian women. Eating behaviors. 2016;22:5-9. 
28. Ostadrahimi A, Nikniaz L, Mahdavi R, Hejazi MA, Nikniaz Z. Effects of synbiotic supplementation on lactating mothers' energy intake and BMI, and infants' growth. Int J Food Sci Nutr. 2013;64(6):711-4.

29. Jia X, Wang D, Eldridge AL, Zhang B, Zhang X, Wang H. Dairy intake would reduce nutrient gaps in Chinese young children aged 3-8 years: a modelling study. Nutrients. 2020;12(2):554.

30. Rozenberg S, Body J-J, Bruyere O, Bergmann P, Brandi ML, Cooper C, et al. Effects of dairy products consumption on health: benefits and beliefs-a commentary from the Belgian Bone Club and the European Society for Clinical and Economic Aspects of Osteoporosis, Osteoarthritis and Musculoskeletal Diseases. Calcif Tissue Int. 2016;98(1):1-17.

31. Moher D, Liberati A, Tetzlaff J, Altman D. Preferred reporting items for systematic reviews and meta-analyses: the PRISMA statement [Guideline Research Support, Non-US Gov't]. Bmj. 2009;339:b2535.

32. The World Bank. 2019 [Available from: https://datahelpdesk.worldbank.org/knowledgebase/articles/906519-world-bankcountry-and-lending-groups. Accessed 2019.

33. Kimura M, Moriyasu A, Kumagai S, Furuna T, Akita S, Kimura S, et al. Community-based intervention to improve dietary habits and promote physical activity among older adults: a cluster randomized trial. BMC geriatrics. 2013;13(1):8.

34. Duncanson K, Burrows T, Collins C. Effect of a low-intensity parent-focused nutrition intervention on dietary intake of 2to 5-year olds. J Pediatr Gastroenterol Nutr. 2013;57(6):728-34.

35. McCarthy WJ, Yancey AK, Harrison GG, Leslie J, Siegel JM. Fighting cancer with fitness: dietary outcomes of a randomized, controlled lifestyle change intervention in healthy African-American women. Preventive medicine. 2007; 44(3):246-53.

36. Casazza K. A computer based approach to improve the dietary and physical activity patterns of a diverse group of adolescents; 2006.

37. DeBar LL, Ritenbaugh C, Aickin M, Orwoll E, Elliot D, Dickerson J, et al. YOUTH: a health plan-based lifestyle intervention increases bone mineral density in adolescent girls. Arch Pediatr Adolesc Med. 2006;160(12):1269-76.

38. DeBar LL, Dickerson J, Clarke G, Stevens VJ, Ritenbaugh C, Aickin M. Using a website to build community and enhance outcomes in a group, multi-component intervention promoting healthy diet and exercise in adolescents. J Pediatr Psychol. 2008;34(5):539-50.

39. Dawson EE. Development of an education curriculum and a self-efficacy scale for dairy nutrition in adolescents: bowling Green State University; 2006.

40. Gates M, Hanning RM, Gates A, Isogai A, Tsuji LJ, Metatawabin J. A pilot comprehensive school nutrition program improves knowledge and intentions for intake of milk and milk alternatives among youth in a remote First Nation. J Nutr Educ Behav. 2013;45(5):455-9.

41. Gates M, Hanning RM, Gates A, McCarthy DD, Tsuji LJ. Assessing the impact of pilot school snack programs on milk and alternatives intake in 2 remote First Nation communities in northern Ontario, Canada. J Sch Health. 2013;83(2):69-76.

42. Lo E, Coles R, Humbert ML, Polowski J, Henry CJ, Whiting SJ. Beverage intake improvement by high school students in Saskatchewan, Canada. Nutr Res. 2008;28(3):144-50.

43. Naghashpour M, Shakerinejad G, Lourizadeh MR, Hajinajaf S, Jarvandi F. Nutrition education based on health belief model improves dietary calcium intake among female students of junior high schools. J Health Popul Nutr. 2014;32(3):420.

44. Olson AL, Gaffney CA, Lee PW, Starr P. Changing adolescent health behaviors: the healthy teens counseling approach. Am J Prev Med. 2008;35(5):S359-S64.

45. O'Connell KM. Impact of the HEROS (Healthy Eating to Reduce Obesity through Schools) Study on healthy food choices and obesity among middle school students in Guilford County (North Carolina) schools: the University of North Carolina at Greensboro; 2005.

46. Singhal N, Misra A, Shah P, Gulati S. Effects of controlled school-based multi-component model of nutrition and lifestyle interventions on behavior modification, anthropometry and metabolic risk profile of urban Asian Indian adolescents in North India. Eur J Clin Nutr. 2010;64(4):364.

47. Watson LC, Kwon J, Nichols D, Rew M. Evaluation of the nutrition knowledge, attitudes, and food consumption behaviors of high school students before and after completion of a nutrition course. Family and Consumer Sciences Research Journal. 2009;37(4):523-34.

48. Wordell D, Daratha K, Mandal B, Bindler R, Butkus SN. Changes in a middle school food environment affect food behavior and food choices. J Acad Nutr Diet. 2012;112(1):137-41.

49. Yamaoka K, Watanabe M, Hida E, Tango T. Impact of group-based dietary education on the dietary habits of female adolescents: a cluster randomized trial. Public health nutrition. 2011;14(4):702-8.

50. Finnell KJ, John R, Thompson DM. $1 \%$ low-fat milk has perks!: an evaluation of a social marketing intervention. Prev Med Rep. 2017:5:144-9.

51. Bernstein MA, Nelson ME, Tucker KL, Layne J, Johnson E, Nuernberger A, et al. A home-based nutrition intervention to increase consumption of fruits, vegetables, and calcium-rich foods in community dwelling elders. J Am Diet Assoc. 2002;102(10):1421-7.

52. Ni Mhurchu C, Blakely T, Jiang Y, Eyles HC, Rodgers A. Effects of price discounts and tailored nutrition education on supermarket purchases: a randomized controlled trial. Am J Clin Nutr. 2009;91(3):736-47.

53. Foster GD, Karpyn A, Wojtanowski AC, Davis E, Weiss S, Brensinger C, et al. Placement and promotion strategies to increase sales of healthier products in supermarkets in low-income, ethnically diverse neighborhoods: a randomized controlled trial. Am J Clin Nutr. 2014:99(6):1359-68.

54. Freedman MR, Nickell A. Impact of after-school nutrition workshops in a public library setting. J Nutr Educ Behav. 2010; 42(3):192-6.

55. Friedman LA, Snetselaar L, Stumbo P, Van Horn L, Singh B, Barton BA. Influence of intervention on beverage choices: trends in the Dietary Intervention Study in Children (DISC). J Am Diet Assoc. 2007;107(4):586-94.

56. Hovell MF, Nichols JF, Irvin VL, Schmitz KE, Rock CL, Hofstetter CR, et al. Parent/child training to increase preteens' calcium, physical activity, and bone density: a controlled trial. Am J Health Promot. 2009;24(2):118-28.

57. Raby Powers A, Struempler BJ, Guarino A, Parmer SM. Effects of a nutrition education program on the dietary behavior and nutrition knowledge of second-grade and third-grade students. J Sch Health. 2005;75(4):129-33.

58. Daniels N, Bryant J, Castano R, Dantes OG, Khan KS, Pannarunothai S. Benchmarks of fairness for health care reform: a policy tool for developing countries. Bull World Health Organ. 2000;78:740-50. 
59. Lapão LV. The challenge of benchmarking health systems: is ICT innovation capacity more systemic than organizational dependent? Isr J Health Policy Res. 2015;4(1):43.

60. Wollum A, Burstein R, Fullman N, Dwyer-Lindgren L, Gakidou E. Benchmarking health system performance across states in Nigeria: a systematic analysis of levels and trends in key maternal and child health interventions and outcomes, 2000-2013. BMC Med. 2015;13(1):208.

61. Van den Brink-Muinen A, Rijken P. Does trust in health care influence the use of complementary and alternative medicine by chronically ill people? BMC Med. 2006;6(1):188.

62. Ozawa S, Walker DG. Comparison of trust in public vs private health care providers in rural Cambodia. Health Policy Plan. 2011;26(suppl_1):i20-i9.

63. Okello DR, Gilson L. Exploring the influence of trust relationships on motivation in the health sector: a systematic review. Hum Resour Health. 2015;13(1):16.

64. Forman-Hoffman VL, Zolotor AJ, McKeeman JL, Blanco R, Knauer SR, Lloyd SW, et al. Comparative effectiveness of interventions for children exposed to nonrelational traumatic events. Pediatrics. 2013;131(3):526-39.

65. Metcalf B, Henley W, Wilkin T. Effectiveness of intervention on physical activity of children: systematic review and metaanalysis of controlled trials with objectively measured outcomes (EarlyBird 54). Bmj. 2012;345:e5888.

66. Kuhaneck HM, Madonna S, Novak A, Pearson E. Effectiveness of interventions for children with autism spectrum disorder and their parents: a systematic review of family outcomes. Am J Occup Ther. 2015;69(5):6905180040p1-p14.

67. Newman E, Pfefferbaum B, Kirlic N, Tett R, Nelson S, Liles B. Meta-analytic review of psychological interventions for children survivors of natural and man-made disasters. Curr Psychiatry Rep. 2014;16(9):462.

68. Fraser JG, Lloyd S, Murphy R, Crowson M, Zolotor AJ, Coker-Schwimmer E, et al. A comparative effectiveness review of parenting and trauma-focused interventions for children exposed to maltreatment. J Dev Behav Pediatr. 2013;34(5):353-68.

69. Van Sluijs EM, McMinn AM, Griffin SJ. Effectiveness of interventions to promote physical activity in children and adolescents: systematic review of controlled trials. Bmj. 2007;335(7622):703.

70. Birch LL, McPhee L, Shoba B, Pirok E, Steinberg L. What kind of exposure reduces children's food neophobia?: looking vs. tasting. Appetite. 1987;9(3):171-8.

71. Young HM. Challenges and solutions for care of frail older adults. Online J Issues Nurs. 2003;8(2):5.

72. Rizvi AA. Nutritional challenges in the elderly with diabetes. International journal of diabetes mellitus. 2009;1 (1):26-31.

73. Duperrex O, Bunn F, Roberts I. Safety education of pedestrians for injury prevention: a systematic review of randomised controlled trials. BMJ. 2002;324(7346):1129.

74. Bailey TM, Delva J, Gretebeck K, Siefert K, Ismail A. A systematic review of mammography educational interventions for low-income women. Am J Health Promot. 2005;20(2):96-107.

75. Menezes MM, Lopes $C T$, de Souza Nogueira L. Impacto de intervenções educativas na redução das complicações diabéticas: revisão sistemática. Rev Bras Enferm. 2016;69(4):773-84.

76. Grillo MFF, Neumann CR, Scain SF, Rozeno RF, Gross JL, Leitão CB. Efeito de diferentes modalidades de educação para o autocuidado a pacientes com diabetes. Revista da associação médica brasileira. 2013;59(4):400-5.

77. Guevara JP, Wolf FM, Grum CM, Clark NM. Effects of educational interventions for self management of asthma in children and adolescents: systematic review and meta-analysis. Bmj. 2003:326(7402):1308-9.

78. Plante L. A guide for entrepreneurs who lead and manage change. Technology Innovation Management Review. 2012; 2(3):27-31.

79. Ryan P. Integrated theory of health behavior change: background and intervention development. Clinical nurse specialist CNS. 2009;23(3):161.

\section{Publisher's Note}

Springer Nature remains neutral with regard to jurisdictional claims in published maps and institutional affiliations.

Ready to submit your research? Choose BMC and benefit from:

- fast, convenient online submission

- thorough peer review by experienced researchers in your field

- rapid publication on acceptance

- support for research data, including large and complex data types

- gold Open Access which fosters wider collaboration and increased citations

- maximum visibility for your research: over 100M website views per year

At BMC, research is always in progress.

Learn more biomedcentral.com/submissions 